Case Report

\title{
Post-Radiation Sphenoidal Mucocele in a Patient Treated for Nasopharyngeal Cancer
}

\author{
Makram Tbini, MD*; Souheil Jbali, MD; Skander Kedous, MD; Mohamed Abderraouf Harhira, MD; Sawssen Dhambri, MD; \\ Zied Attia, MD; Slim Touati, MD; Said Gritli, MD
}

Otorhinolaryngology-Head and Neck Surgery Department, Salah Azaiez Institute of Oncology, Tunis, Tunisia

\section{*Corresponding author}

Makram Tbini, MD

Otorhinolaryngology-Head and Neck Surgery Department, Salah Azaiez Institute of Oncology,Tunis, Tunisia;Tel. +216 21266616; E-mail: makramtb@yahoo.com

\author{
Article information \\ Received: March 28 $8^{\text {th }}, 2018$; Revised: April 26 ${ }^{\text {th }}, 2018$; Accepted: June 21 ${ }^{\text {st }}, 2018$; Published: July $18^{\text {th }}, 2018$
}

\section{Cite this article}

Tbini M, Souheil J, Kedous S, et al. Post-radiation sphenoidal mucocele in a patient treated for nasopharyngeal cancer. Otolaryngol Open J. 2018; 4(I): I5-17. doi: 10.17|40/OTLOJ-4-147

\section{ABSTRACT}

The paranasal sinus mucoceles are epithelial-lined cystic lesions containing mucus or mucopurulent fluid. Several theories have been advanced to explain their occurrence. Previous trauma and sinus surgery are the most common cause. Mucoceles following radiotherapy are rare.

We report the case of a sphenoidal mucocele in a 62-year-old woman who had received radiotherapy 13 years ago for a nasopharyngeal carcinoma. Marsupialisation through an endoscopic transnasal approach was performed. No evidence of recurrence seen after 12 months of follow-up.

\section{Keywords}

Mucocele, Sphenoid sinus, Nasopharyngeal cancer, Radiotherapy.

\section{INTRODUCTION |}

$\mathrm{M}$ ucoceles are benign rare cystic tumours which may originate from any sinus cavities when their natural ostia are blocked. As there is no drainage pathway in these closed sacs, the mucocele expands as the secretions collect. As a result, it exerts pressure on the surrounding structures. ${ }^{1}$ Previous trauma and sinus surgery are the most common cause. Mucoceles following radiotherapy are rare. They occur usually after irradiation for a nasopharyngeal cancer in the sphenoid sinus. Few cases have been reported in literature. $^{2}$

The aim of this article is to report the importance of clinical and radiological follow-up in patients treated from nasopharyngeal cancer, not only to detect tumour recurrences but also complications such as mucoceles.

\section{CASE REPORT}

A 62-year-old woman with a history of undifferentiated nasopharyngeal carcinoma (T2 N0 M0), treated with radiotherapy 13-years-ago, was referred to our department with the complaint of bilateral nasal obstruction and headaches for 11 months.

Ears, nose and throat (ENT) examination and nasal fibroendoscopy revealed no abnormalities. Neurological and ophthalmological examination were normal.

So magnetic resonance imaging (MRI) was performed looking for tumour recurrence and showed a cystic lesion with a high signal intensity on T1-weighted image and a low signal intensity on T2-weighted image, limited in the sphenoid sinus (Figures 1 and 2).

Therefore, the sphenoid sinus was approached under general anaesthesia through an endoscopic approach. A biopsy of the sphenoid sinus and marsupialisation of the mucocele were performed. But no malignant cells were found in histological examination.

Patient had an uneventful post-operative course with no evidence of recurrence seen after 12 months of follow-up. 

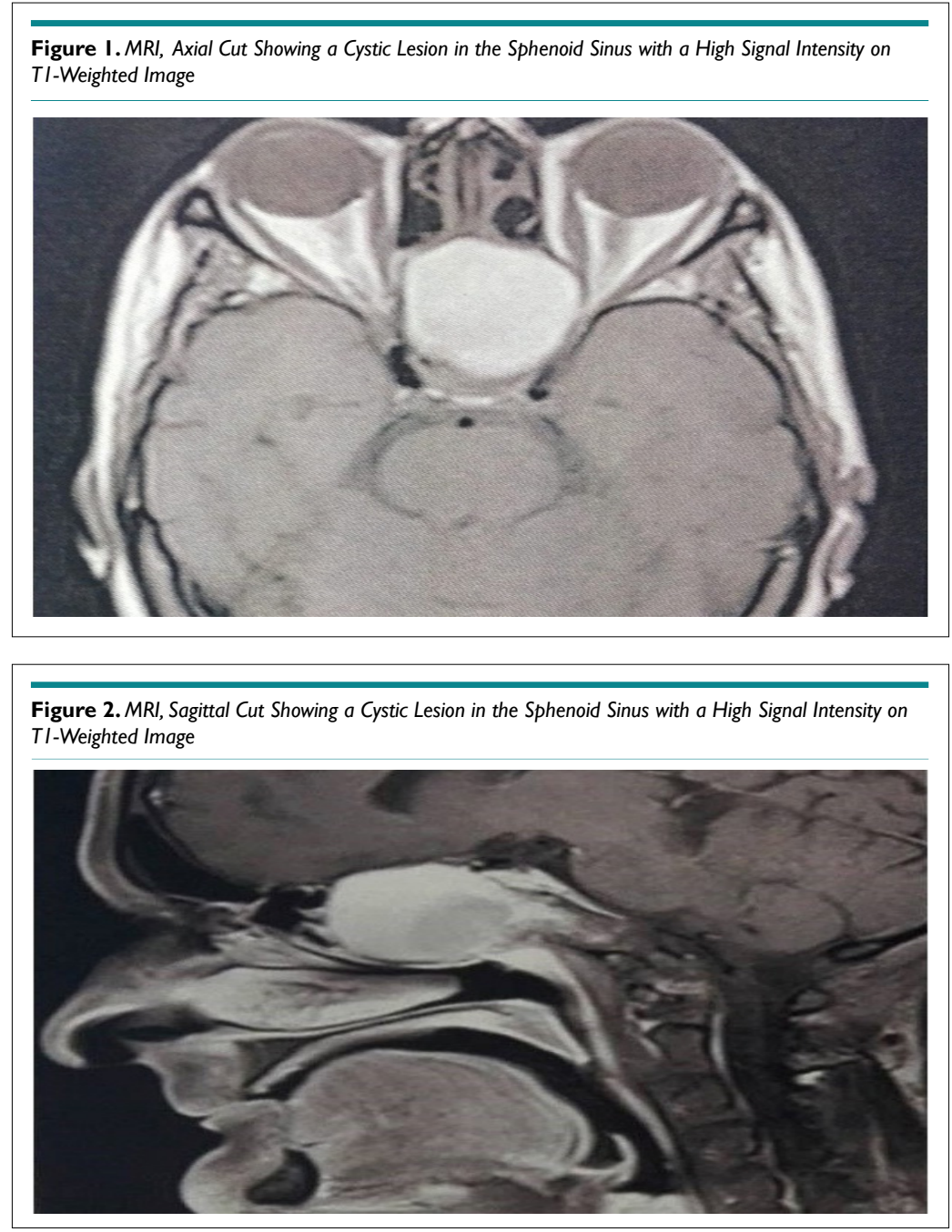

\section{DISCUSSION}

Paranasal sinusmucoceles are benign pseudocystictumors, they have an expansive and destructive tendency and a slow evolution. ${ }^{1}$

All locations are possible; they are frequently found in the frontal sinus, the anterior ethmoidal sinus, the maxillary sinus, while posterior ethmoidal sinus and sphenoid sinus are rarely affected (less than $1 \%)^{3}$

Ostial obstruction have been advanced to explain their etiopathogenesis. Mucocele predisposing factors include chronic rhinosinusitis, allergic rhinitis, cranio-facial trauma, sinus surgery, nasosinusaltumors, and radiotherapy. ${ }^{4,5}$

Mucoceles have been reported to be more frequent in men, with a peak incidence in the third or fourth decade of life.

Few cases of mucocele occurring after radiation therapy for tumors of the head and neck region were reported in the literature. Irradiation for nasopharyngeal carcinoma and sphenoidal seat are the most frequently reported., ${ }^{2,5,-9}$

Radiotherapy can cause obstruction of the sinus ostium by induced fibrosis. ${ }^{5,7,8}$

Mucoceles can cause various signs and symptoms, depending on the affected area; those symptoms can be rhinological, ophthalmic or neurological. ${ }^{10}$

Imaging is essential for the diagnosis and management of paranasal sinusmucoceles, it is based on computerized tomography (CT) scan and MRI. ${ }^{11,12}$

On CT-scan, mucoceles can be hypodense, isodense or hyperdense with peripheral enhancement after injection of contrast agents, bone erosion can be found. This variability on densities is due to their protein content, inspissation and possible surinfection. At MRI, the signal of the mucocele is also variable depending on the viscosity and protein content. Mucocele generally presents a low signal intensity on T1-weighted image, a high signal intensity on T2-weighted image with enhancement of its wall after injection of gadolinium. For old forms, mucoceles present a low signal intensity on T1 and T2, but other forms of signal intensity can be found. ${ }^{11,13}$

Therefore, imaging is useful to rule outother lesions in the sphenoid sinus and the skull base that may mimic sphenoidal mucocele such as necrotic primary adenoma with significant in- 
trasellar extension, craniopharyngioma, chordoma, plasmacytoma, osteoma, osteoblastoma, basal cell and squamous cell carcinoma, rhinolitis, polyps, and fibrous dysplasia. ${ }^{14}$

In all cases, mucoceles treatment must be surgical and depends on the location of the mucocele and its extension, and can be through endoscopic, external or combined approach. Nevertheless, endoscopic marsupialization has become the surgical approach of choice given its low morbidity, short time procedure, reduced damage to the nasal structure and physiology, good functional results and rapid patient discharge. ${ }^{12,15}$

Finally, a regular clinical and radiological follow-up after surgery is essential in order to look for tumor or mucocele recurrence and for complications such synechiae. ${ }^{4,14}$

\section{CONCLUSION}

Sphenoidal mucocele is a possible complication of radiotherapy in patients with nasopharyngeal carcinoma that can mimic recurrence. Computerized tomography scan and magnetic resonance imaging can confirm the diagnosis. Endoscopic approach is the optimal method of treatment.

\section{CONFLICTS OF INTEREST}

The authors have no conflict of interest.

\section{CONSENT}

An informed consent has been obtained from the patient.

\section{REFERENCES}

1. Zukin LM, Hink EM, Liao S, Getz AE, Kingdom TT, Ramakrishnan VR. Endoscopic management of paranasal sinus mucoceles: Meta-analysis of visual outcomes. Otolaryngol Head Neck Surg. 2017; 157(5): 760-766. doi: 10.1177/0194599817717674

2. Mnejja M, Hammami B, Achour I, et al. Post-radiation mucocele in two patients treated for nasopharyngeal cancer [In French]. Cancer radiother. 2011; 15(3): 254-256. doi: 10.1016/j.canrad.2010.12.004

3. Morita S, Mizoguchi K, Iizuka K. Paranasal sinus mucoceles with visual disturbance. Auris Nasus Larynx. 2010; 37(6): 708-712. doi: 10.1016/j.anl.2010.04.002

4. Devars du Mayne M, Moya-Plana A, Malinvaud D, Laccourreye O, Bonfils P. Sinus mucocele: natural history and long-term recur- rence rate. Eur Ann Otorbinolaryngol Head Neck Dis. 2012; 129(3): 125-130. doi: 10.1016/j.anorl.2011.10.002

5. Wong CS, Luk SH, Leung TW, Yuen KK, Sze WK, Tung SY. Sphenoid sinus mucocoele and cranial nerve palsies in a patient with a history of nasopharyngeal carcinoma: May mimic local recurrence. Clin Oncol (R Coll Radiol). 2001; 13(5): 353-355.

6.Capra GG, CarbonePN, Mullin DP. Paranasal sinus mucocele. Head Neck Pathol. 2012; 6(3): 369-372. doi: 10.1007/s12105-012-0359-2

7. Lin JY, Lin SL, Chang YL, Lo SH, Chuang FS, Lin SY. Sphenoid sinus mucocoele presenting with optic neuropathy and abducens palsy: A late complication of radiotherapy to the head and neck. Eye. 2005; 19(6): 697-699. doi: 10.1038/sj.eye.6701581

8. Rejab E, Said H, Saim L, Thim L. Sphenoid sinus mucocoele: A possible late complication of radiotherapy to the head and neck. $J$ Laryngol Otol. 1991; 105(11): 959-960.

9. Sharouny H, Narayanan P. Maxillary Sinus Mucopyocele in a fifty-eight-year-old man: A possible late complication of irradiation to head and neck. Iranian Red Crescent Med J. 2014; 16(7): e17133. doi: $10.5812 /$ ircmj.17133

10. Santos PLD, Chihara LL, Alcalde LFA, Masalskas BF, Sant'Ana E, Faria PEP. Outcomes in surgical treatment of mucocele in frontal sinus. J Craniofac Surg. 2017; 28(7): 1702-1708. doi: 10.1097/ SCS.0000000000003224

11. Marrakchi J, Nefzaoui S, Chiboub D, et al. Imaging of paranasal sinus mucoceles. Otolaryngol Open J. 2016; 2(3): 94-100. doi: 10.17140/OTLOJ-2-121

12. Topdag M, Iseri M, Sari F, Erdogan S, Keskin IG. Paranasal sinus mucoceles: Our clinical experiments. Int J Clinical Exp Med 2015; 8(10): 18518-18522.

13. Kosling S, Hintner M, Brandt S, Schulz T, Bloching M. Mucoceles of the sphenoid sinus. Eur J Radiol. 2004; 51(1): 1-5.

14. Caballero Garcia J, Giol Alvarez AM, Morales Perez I, Gonzales Gonzales N, Hidalgo Gonzales A, Cruz Perez PO. Endoscopic treatment of sphenoid sinus mucocele: Case report and surgical considerations. Case Rep Otolaryngol. 2017; 2017: 7567838.

15. Waizel-Haiat S, Díaz-Lara IM, Vargas-Aguayo AM, Santiago-Cordova JL. Experience in the surgical treatment of paranasal sinus mucoceles in a university hospital. Cirugia y Cirujanos. [English Edition]. 2017; 85(1): 4-11. 